OPEN ACCESS

Edited by:

Arend Bos,

University Medical Center Groningen, Netherlands

Reviewed by:

Anne Lee Solevåg

Akershus University Hospital, Norway

Stefano Nobile,

A. Gemelli University Hospital Foundation (IRCCS), Italy

${ }^{*}$ Correspondence:

Eugene M. Dempsey g.dempsey@ucc.ie

Specialty section:

This article was submitted to Neonatology,

a section of the journal

Frontiers in Pediatrics

Received: 06 October 2020 Accepted: 15 December 2020 Published: 28 January 2021

Citation:

O'Neill R, Dempsey EM, Garvey AA and Schwarz CE (2021) Non-invasive Cardiac Output Monitoring in Neonates. Front. Pediatr. 8:614585. doi: 10.3389/fped.2020.614585

\section{Non-invasive Cardiac Output Monitoring in Neonates}

\author{
Roisin O’Neill ${ }^{1,2}$, Eugene M. Dempsey ${ }^{1,2,3 *}$, Aisling A. Garvey ${ }^{1,2,3}$ and \\ Christoph E. Schwarz ${ }^{2,3,4}$
}

${ }^{1}$ Department of Neonatology, Cork University Maternity Hospital, Cork, Ireland, ${ }^{2}$ Department of Paediatrics and Child Health, University College Cork, Cork, Ireland, ${ }^{3}$ Irish Centre for Maternal and Child Health Research (INFANT) Research Centre, University College Cork, Cork, Ireland, ${ }^{4}$ Department of Neonatology, University Children's Hospital, Tübingen, Germany

Circulatory monitoring is currently limited to heart rate and blood pressure assessment in the majority of neonatal units globally. Non-invasive cardiac output monitoring (NiCO) in term and preterm neonates is increasing, where it has the potential to enhance our understanding and management of overall circulatory status. In this narrative review, we summarized 33 studies including almost 2,000 term and preterm neonates. The majority of studies evaluated interchangeability with echocardiography. Studies were performed in various clinical settings including the delivery room, patent ductus arteriosus assessment, patient positioning, red blood cell transfusion, and therapeutic hypothermia for hypoxic ischemic encephalopathy. This review presents an overview of NiCO in neonatal care, focusing on technical and practical aspects as well as current available evidence. We discuss potential goals for future research.

Keywords: systemic blood flow, bioimpedance, electrical cardiometry, bioreactance, circulatory monitoring, transthoracic electrical biosensing technology, electrical velocimetry

\section{INTRODUCTION}

Monitoring and assessment of the cardiovascular system is an essential component in the care of term and preterm infants in neonatal intensive care units. Current methods of evaluation rely mainly on available bedside parameters, including blood pressure (BP), heart rate (HR), capillary refill time, and urine output, in conjunction with biochemical markers of tissue perfusion such as lactate. There are many limitations of these measurements. BP (1-4), capillary refill time (3-6), and urine output (4) do not correlate well with systemic blood flow, and HR can be easily influenced by other factors including medication, pain, and fever.

In order to accurately evaluate the cardiovascular status, two other factors need to be considered: cardiac output (CO) and systemic vascular resistance (SVR). Together, these determine systemic blood flow and subsequently end organ perfusion. The current standard measurement of $\mathrm{CO}$ in the neonatal unit is bedside echocardiography (Echo), as more invasive gold standard methods such as thermodilution have limited applicability and feasibility in the neonatal population. Echo use in the neonatal intensive care unit has grown exponentially over the last decade and has improved the evaluation of infants with suspected cardiovascular instability (7). However, Echo is not without limitations. Findings depict a single point in time, and extensive standardized training is required to ensure the quality of the measurements, before it can be safely implemented as a tool for cardiac assessment in neonatal intensive care units $(8,9)$. Despite standardization, accuracy and intra/interobserver variability remain an issue. There is also the risk of destabilizing an infant, given that a full cardiac assessment with echo can take a considerable period of time. 
Given these problems, other methods need to be considered. Non-invasive cardiac output monitoring (NiCO) has the potential to provide continuous real-time measurements at the bedside. Initial studies in adults have shown it to have acceptable accuracy and precision $(10,11)$. However, like any new device, it should be validated. The ideal technology should fulfill certain criteria: (a) validated against gold standard; (b) accurate and precise; (c) easily applicable, non-invasive, and inexpensive; (d) continuous and easy to interpret; and (e) accurate in the presence of shunts and postnatal transition $(12,13)$. In reality, there is no perfect assessment method for cardiac evaluation in the neonatal population. There has been an increasing number of studies completed using $\mathrm{NiCO}$ in neonates over the last 10 years. The objective of this narrative review is to summarize the use of $\mathrm{NiCO}$ in neonatal care, focusing on both the specific areas of clinical utility and its limitations. In doing so, we aim to highlight where future research should be focused.

\section{TECHNICAL BACKGROUND}

NiCO derives from the principle of impedance. This is the measure of opposition to the flow of an alternating electrical current. The complex impedance consists of two components: the real (resistive) and the imaginary (capacitive and inductive) components, and these are known to change over time in relation to the cardiac cycle. Impedance cardiography, also known as "thoracic electrical bioimpedance," is the study of cardiac function determined from the measurements of electrical impedance within the thorax (14). In traditional bioimpedance systems, an electrical current of known amplitude and frequency is passed through the thorax, and the change in voltages are measured. The first monitoring device was described by Kubicek et al. in 1966, who had been commissioned by NASA to create a non-invasive way of measuring cardiac output (15). Within the thorax, there are various structures and each will "impede" current differently. Blood is known to have a lower resistance to electrical current than other tissues. Impedance to electrical flow will also vary at different timepoints within the cardiac cycle, particularly during systole as blood is pumped into the aorta, causing a sharp decrease in electrical resistance within the thorax. This principle is used to estimate hemodynamic parameters such as stroke volume (SV) and CO. With advances in technology and a greater understanding of cardiac physiology, these models have been updated and adapted, and modifications made to the original mathematical algorithms to improve the quality of the results obtained. The two most recent models used for estimating $\mathrm{CO}$ in neonates non-invasively are electrical cardiometry (EC) and bioreactance (BR). Other technologies including signalmorphology impedance cardiology exist, but have not yet been utilized in neonates.

\section{Electrical Cardiometry}

Bernstein and Osypka developed and described the technical background of EC, a new model for interpreting thoracic bioimpedance (16). EC uses four electrodes: two outer (head and thigh) and two inner (neck and thorax) electrodes. An alternating electrical current is applied through the two outer electrodes, and the resulting voltage is measured by the corresponding inner electrode (17). EC uses the length of the impedance vector, determined by the real and the imaginary component of impedance, and its changes in time in relation to the cardiac cycle. During diastole and prior to the aortic valve opening, red cells in the aorta are orientated in a random distribution with increased resistance to an electrical current. During systole when blood is pumped into the aorta, red cells will align resulting in a change in conductivity. By analyzing the speed of these changes, EC technology estimates peak aortic acceleration of blood flow, left ventricular (LV) pre-ejection period and ejection time (PEP and ET). This is used within the EC algorithm to derive stroke volume, and using simultaneous measurements of HR obtained from the electrocardiogram, CO is estimated. This is utilized on the Aesculon and ICON device (Osypka Medical, Berlin, Germany/Cardiotronic, San Diego, CA, USA).

\section{Bioreactance}

BR is based on the "imaginary" component of the impedance, that is the capacitive and inductive properties of blood and biological tissue that induces phase shifts between an applied electrical current and the resulting voltage signal $(10,18,19)$. This is different from bioimpedance, which uses the "resistive" component of blood and tissues to determine a change in voltage after an electrical current of known amplitude and frequency is applied across the thorax. Changes in thoracic blood volume occur with each heartbeat, and this causes an instantaneous change in the phase shift between an applied current and the measured voltage signal (19). This measured change is directly related to SV and, in conjunction with $\mathrm{HR}$, can subsequently determine CO. The Cheetah NICOM/StarlingSV (Cheetah Medical Inc., Newton, MA, USA) is somewhat different from the EC technology highlighted above. Each sensor consists of two electrodes: one applying an alternating current and the other one sensing. The device measures a phase shift, also known as a time delay, between the measured thoracic voltage and the applied current (18). These phase shifts are directly related to blood flow occurring in the large thoracic arteries, with larger volumes of blood causing an increase in phase shifts. Sensors from the right side and left side of the thorax are paired together, and measurements from both sides are then averaged to estimate SV and CO.

\section{Important Practical Considerations for User Sensor Size and Application}

The sensor itself and sensor application are very different between EC and BR (Figure 1). BR uses four dual electrode stickers $(\sim 95 \times 28-40 \mathrm{~mm}$ each with two circular shaped electrodes with a diameter of $25 \mathrm{~mm}$ ), positioned in a "box" surrounding the heart: two sensors on the right side and two on the left side of the body (Figure 2A). Given the relatively large surface area of these sensors, application in newborns is challenging. Different solutions have been published including cutting down the adhesive component of the sensors and altering the placement positions (20-23). On the other hand, EC has specific neonatal sensors, which are smaller in size $(25 \times$ 


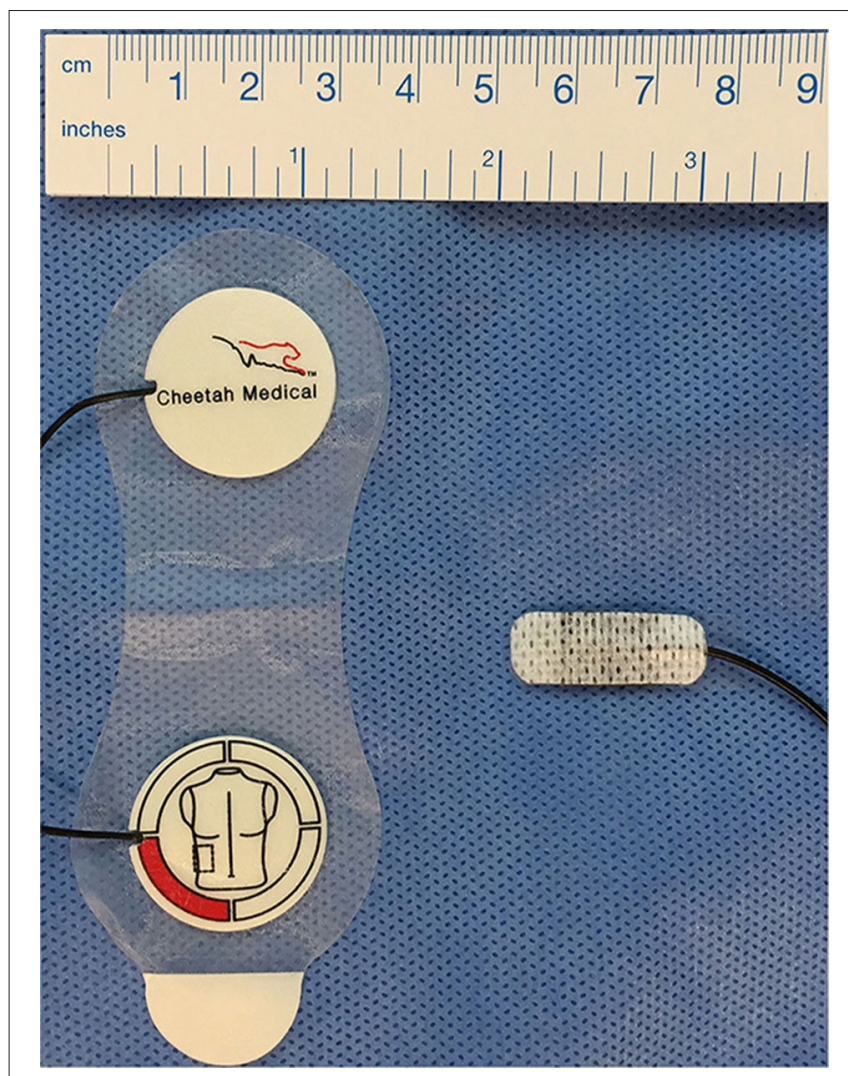

FIGURE 1 | Bioreactance and electrical cardiometry electrodes. Left: Duo-electrode sensors for bioreactance monitoring (Cheetah Medical Inc., Newton, MA, USA), right: ISense neonatal sensors for electrical cardiometry monitoring (Osypka Medical, Berlin, Germany).

$10 \mathrm{~mm}$ ). Previously, sensors have been placed on the head, left side of neck, left thorax (at the level of the xyphoid), and left outer thigh. Recently, there have been adaptions made by the manufacturer, with regard to the ideal placement of sensors. They now recommend that the neck probe should be placed on the right side of the neck, and that the legprobe should be placed on the inner thigh for improved accuracy (Figure 2B).

\section{Calibration/Adaption for Bodyweight and Length}

EC uses an internal calibration, which takes into account the neonate's bodyweight and length for SV and CO estimates, to adjust for effects on distance between sensors (17). This is necessary to address different distances between emitters and sensors regarding the size of the infants. BR does not take into account differences in body length directly, but the algorithm accounts for age, gender, and body size based on data from adult population (18).

\section{Signal Quality}

The StarlingSV/Cheetah does not display or log values during periods with low signal quality. Rather, no value is displayed. EC devices display signal quality estimated automatically as a
A

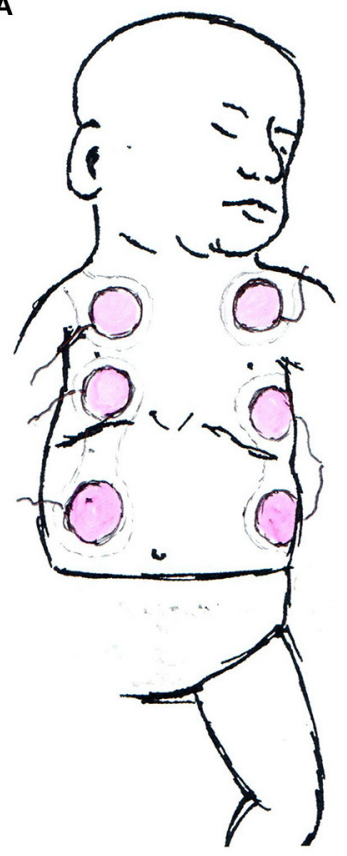

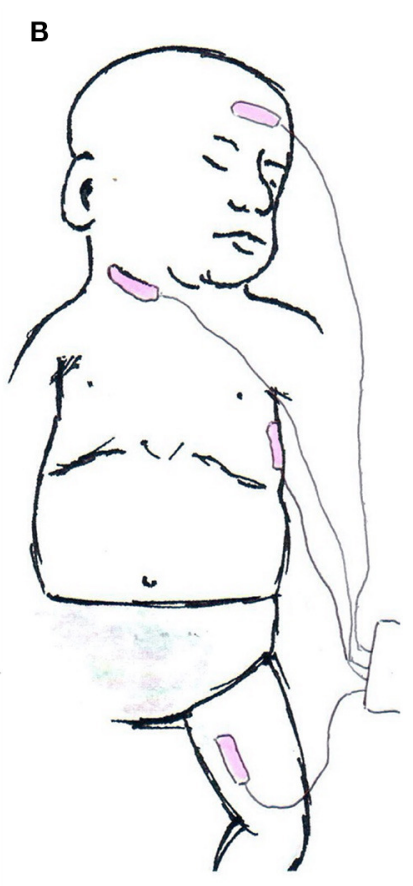

FIGURE 2 | Schematic examples for electrode application. (A) Example of Bioreactance electrode placement in neonates. The upper part of the shoulder electrodes is crossing the shoulder and not visible from the anterior. (B) Current manufacturers' recommendation of sensor application in electrical cardiometry monitoring.

percentage representing the proportion of good signal quality cardiac cycles obtained over the preceding 10 cardiac cycles.

\section{Frequency of Data Logging}

Unaveraged data with beat-to-beat resolution is not available on the StarlingSV at present. The minimum logging interval is now $4 \mathrm{~s}$. Internally, the StarlingSV is estimating the CO every beat, but data is averaged over the preceding $24 \mathrm{~s}$. This averaging interval is divided into $8 \mathrm{~s}$ episodes, and within each episode, a minimum of two analyzable beats are required (direct communication with the distributor). However, all neonatal studies using BR in this review, used data logged and subsequently averaged over a minute by minute basis. In contrast, EC devices provide beatto-beat values, as well as various averaging and logging intervals starting with a minimum of $5 \mathrm{~s}$. The principle of unaveraged beat-to-beat resolution may be more relevant in the research setting, rather than in day to day clinical care.

\section{FEASIBILITY STUDIES}

These studies were primarily focused on the use of $\mathrm{NiCO}$ in the delivery room. They investigated whether it was possible to both apply the sensors, and to obtain values in the immediate postnatal period. Katheria et al. (24) looked at the feasibility of using EC within the first $5 \mathrm{~min}$ after delivery in 20 vaginally delivered term infants with an intact cord. The first signal/reading was 
available at a median time of $89 \mathrm{~s}$ of life [IQR $[83,116]]$. No data was recorded in the first minute, and $\sim 50 \%$ of the subjects had data available between 1 and 2 min of life. As mentioned previously, the EC algorithm relies on both weight and length to calibrate accurately the absolute values of CO. Given this was not available immediately after birth, the measurements recorded are only useful as a trend monitor. Freidl et al. (25) also used EC to monitor term infants in the delivery room for the first $15 \mathrm{~min}$ of life. They determined questionable feasibility, given that $76.2 \%$ of the measurements had to be excluded because of a signal quality index $<80 \%$. More recently, a study carried out by our hospital group evaluated the role of BR in the delivery room on a cohort of 49 babies. Values were obtained at a median time of $3 \mathrm{~min}$ from application of sensors. Again, trend values were obtained over the first $15-20$ min of life and compared to values obtained at $\sim 2 \mathrm{~h}$ of age (26).

\section{ACCURACY STUDIES}

\section{Interchangeability to Echocardiography}

The vast majority of publications address the accuracy of EC or $\mathrm{BR}$, as the direct interchangeability to Echo (as the reference method). A range of prospective observational studies have been carried out, and collectively include over 300 preterm and more than 100 term infants (Table 1). However, it is important to understand the implications of comparing EC/BR to a reference method such as Echo, which also has shortcomings in both precision and accuracy. The limit of precision of Echo compared with the gold standard method of dilution technique is $\sim 30 \%$, which is within the clinically accepted range (38). This is also in line with comparison of Echo to cardiac magnetic resonance imaging studies revealing a repeatability index of $28.2 \%$ (39).

Critchley et al. (40) published a meta-analysis of studies which had used bias and precision to compare $\mathrm{CO}$ estimation techniques ( $\mathrm{NiCO}$ vs. Echo). The authors identified a $30 \%$ percentage error to be clinically acceptable (40). In a systematic review and meta-analysis of $\mathrm{CO}$ measurements in children, the $\mathrm{NiCO}$ method was identified as being the most accurate and precise, when compared to other non-invasive or invasive techniques used to monitor CO (41). However, a subgroup analysis looking at age below 1 year identified a pooled bias of $-0.08 \mathrm{~L} / \mathrm{min}$ and a percentage error of $33.2 \%$ compared to Echo (41). This would suggest non-interchangeability in this age group. Of note, this analysis was limited to only two studies in term and near-term infants $(17,21)$. A more recent systematic review focusing on EC (42) included neonates in a subgroup of pediatric studies (2 studies out of 11) (17, 32, 42). Van Wyk et al. (20) recently summarized the available literature on reproducibility of $\mathrm{NiCO}$ and Echo addressing the limited precision of Echo. In line with the previous definition, interchangeability of the two methods was assumed when the combined percentage error is $<42 \%$ (equal to $\sqrt{ }\left[30^{2}+30^{2}\right]$ ). As part of this review, we identified nine studies on EC (17, $27-33,35)$ and four studies on $\operatorname{BR}(21,36,37)$ in neonatal care. In line with Van Wyk et al. (20) we conclude that the $\mathrm{NiCO}$ is not interchangeable with Echo for CO measurement. Interpreting $\mathrm{NiCO}$ derived values with thresholds based on Echo values is problematic. As EC monitors display and log estimates of signal quality, studies investigating interchangeability with Echo used cutoffs for signal quality index of $>70 \%$, thus accounting for poor signal quality $(17,32,33,35)$. This might explain differences in reproducibility in EC compared to BR studies.

\section{Confounding Factors on Accuracy}

Respiratory support in preterm infants is common and often includes both non-invasive and invasive ventilation techniques. These have been shown to affect the accuracy of EC and BR, especially during periods of high-frequency oscillation $(20,21$, 29). Other co-morbidities related to immaturity, including shunts such as a PDA, have also been identified as confounders (32). Depending on the degree and the direction of shunting, this can either lead to an underestimate (right-to-left) or an overestimate (left-to-right) of effective systemic blood flow, particularly when using left ventricular CO as a surrogate marker for this (43). In addition, the more common left-to-right shunt through a patent foramen ovale results in an overestimation of systemic venous return by increasing right ventricular (RV) $\mathrm{CO}(36,44,45)$. In a comparison study of EC with Echo in term infants, there was no significant difference in the bias or precision between the two methods, in patients with or without a hemodynamically significant PDA (defined as a diameter $>2 \mathrm{~mm}$ ) (17). On the other hand, in a group of preterm infants using $\mathrm{BR}$, the presence of a PDA was found to significantly affect the accuracy of CO (20). In the same study, they also found that the level of $\mathrm{CO}$ value itself influenced the accuracy of the measurement. Low and high CO situations were found to be less accurate compared to "normal" output ranges (20). As these low or high output states are clinically relevant and important to identify and treat, this may potentially limit the diagnostic value of $\mathrm{NiCO}$.

\section{INVESTIGATED CLINICAL CONDITIONS/SITUATIONS}

In addition to those accuracy and validation studies discussed, EC and BR reported that neonatal studies have also included $\sim 1,000$ preterm and 400 late preterm/term infants across a range of clinical settings. In Table 2, studies investigating NiCO-derived estimates for $\mathrm{SV}$ and/or $\mathrm{CO}$ are summarized.

\section{Delivery Room Management}

Katheria et al. (24) used EC to measure CO within the first 5 min after birth in term infants. Freidl et al. (25) extended this to the first $15 \mathrm{~min}$ after birth. As we have previously highlighted, BR has also been used in the delivery room (26). While there was no direct comparison to Echo in any of these studies, the reported results are comparable to previous data using Echo in the delivery room (64). Delivery room EC is also limited by the fact that the algorithms require birth weight and body length to determine absolute values, as well as body weight indexed values, and thus is limited to trend changes over this time period. 
TABLE 1 | Accuracy studies.

\begin{tabular}{|c|c|c|c|c|}
\hline Study & Technology & Population & Age at measurement [days] & Interchangeability/Systematic bias \\
\hline Noori et al. (17) & EC & 20 "healthy" term & $<3$ & Not interchangeable, no systematic bias \\
\hline Grollmuss et al. (27) & EC & $\begin{array}{l}24 \text { newborns with } \\
\text { transposition of the } \\
\text { great arteries after } \\
\text { switch-OP }\end{array}$ & $10(3-29)$ & Interchangeable, systematic over-reading \\
\hline Grollmuss et al. (28) & EC & 28 preterm & $15(1-48)$ & Interchangeable, systematic over-reading \\
\hline Song et al. (29) & EC & 40 preterm & $<1.5$ & $\begin{array}{l}\text { Not interchangeable except infants in room } \\
\text { air, systematic under-reading except for } \\
\text { over-reading during HFV }\end{array}$ \\
\hline Blohm et al. (30) & EC & $\begin{array}{l}72 \text { total aged } 2 \\
\text { days-17 years } \\
\text { (subgroup } 26 \text { preterm) }\end{array}$ & $\begin{array}{l}\text { Preterm subgroup } 14.6 \\
(3.7-40.2)\end{array}$ & $\begin{array}{l}\text { Not interchangeable in preterm infants } \\
\text { subgroup, systematic under-reading }\end{array}$ \\
\hline Boet et al. (31) & $\mathrm{EC}$ & 59 neonates & NA & $\mathrm{NR}$ \\
\hline Torigoe et al. (32) & EC & 28 preterm & $4(1-13)$ & Interchangeable, no systematic bias \\
\hline Boet et al. (33) & EC & 79 preterm & NA & NR Trend to overestimate \\
\hline Boet et al. (34) & EC & $\begin{array}{l}30 \mathrm{NICU} / \mathrm{PICU} \text { patients } \\
\text { during transportation }\end{array}$ & $29(41)$ & $\begin{array}{l}\text { "Comparable reliability," systematic } \\
\text { over-reading }\end{array}$ \\
\hline Hsu et al. (35) & EC & 36 preterm with hsPDA & $6(2-22)$ & $\begin{array}{l}\text { Interchangeable, but decreased for } \\
\text { respiratory support with HFV, no systematic } \\
\text { bias }\end{array}$ \\
\hline Weisz et al. (21) & $\mathrm{BR}$ & $\begin{array}{l}10 \text { infants with } \mathrm{GA}> \\
31 \text { weeks }\end{array}$ & NA & Interchangeable, systematic under-reading \\
\hline Weisz et al. (36) & $\mathrm{BR}$ & $\begin{array}{l}25 \text { preterm post PDA } \\
\text { ligation }\end{array}$ & $\sim 5-6$ weeks & Interchangeable, systematic under-reading \\
\hline Forman et al. (37) & $\mathrm{BR}$ & $\begin{array}{l}8 \text { term infants } \\
\text { undergoing } \mathrm{TH} \text { for } \mathrm{HIE}\end{array}$ & $<5$ & $\%$ Error NR, systematic under-reading \\
\hline Van Wyk et al. (20) & $\mathrm{BR}$ & 63 preterm & $<3$ & $\begin{array}{l}\text { Not interchangeable, systematic } \\
\text { under-reading }\end{array}$ \\
\hline
\end{tabular}

EC, Electrical Cardiometry; BR, BioReactance; GA, Gestational Age; LV, left ventricular; CO, cardiac output; HFV, High Frequency Ventilation Age in measurements presented in days as mean (SD), median (IQR) or < threshold as reported. Criterion for interchangeability is combined percentage error < $42 \%$; NR is stated if percentage error was not reported.

Cord management strategies are known to impact circulatory parameters in later postnatal transition. In randomized controlled trials of preterm infants $<32$ weeks gestational age (GA) receiving umbilical cord milking (UCM) vs. immediate cord clamping, infants randomized to UCM had higher superior vena cava flow (SVC-flow) and RV CO measured using Echo, but no differences were found for $\mathrm{NiCO}$-derived parameters within the first day of life $(46,65)$.

A separate study looking at two groups of preterm infants randomized to either respiratory support during delayed cord clamping (DCC) $(60 \mathrm{~s})$ or DCC without respiratory support, showed no difference in EC-derived hemodynamic measurements in the first day of life (47).

\section{Transition}

Hemodynamic monitoring in the first few days of life is particularly challenging given the presence of persistent shunts, and the complex physiological changes that occur in the transition from fetal to neonatal circulation (7). Cappelleri et al. (48) investigated changes in left ventricular output in mid-to late preterm infants within the first 2 days of life. Using BR to estimate $\mathrm{LV} \mathrm{CO}$ and SV, they reported an incremental increase in both these parameters, but with a stable HR throughout (48). In a recent study Miletin et al. (23) published BR-derived values for more immature preterm infants between 6 and $48 \mathrm{~h}$ of life in relation to clinically relevant outcomes. In line with Cappelleri et al. (48) they reported lower $\mathrm{CO}$ at $6 \mathrm{~h}$, which increased over the second day of life. Interestingly, this increase was found to be associated with an increased incidence of intraventricular hemorrhage suggesting reperfusion injury as a pathophysiological explanation. Beyond early transition, Hsu et al. (49) published reference values in term and preterm infants without PDA $>72 \mathrm{~h}$ postnatally. Whether NiCO alone (ClinicalTrials.gov NCT04064177), or integrated into multimodal monitoring (ClinicalTrial.gov NCT04538079), results in improved clinical outcome in preterm infants is currently under evaluation.

\section{Patent Ductus Arteriosus}

PDA is still one of the most controversial areas of preterm management. EC was used to evaluate the early $(<24 \mathrm{~h})$ prediction of significant PDA in preterm infants (51). This so-called hemodynamically significant (hs) PDA is not clearly defined. However, the authors found that Echo-derived LV CO was predictive for hsPDA. Infants treated for a PDA were found to have lower mean $\mathrm{BP}, \mathrm{CO}$, and SV compared to untreated, but after adjustment for GA and birth weight, all parameters except mean BP were found to be non-significant. In contrast, Rodríguez et al. (52) monitored infants undergoing treatment of PDA (three ibuprofen doses) using EC. They reported a significant decrease in CO indexed for body weight (0.24 vs. $0.29 \mathrm{~L} / \mathrm{kg} / \mathrm{min}$; P 0.03) after $72 \mathrm{~h}$. Hsu et al. (53) found infants with PDA had higher 
TABLE 2 | NiCO in various scenarios.

\begin{tabular}{lccc}
\hline Topic Study & Technology & $\boldsymbol{N}$ & Population \\
\hline $\begin{array}{ccc}\text { Delivery room and postnatal management } \\
\text { Katheria et al. (46) }\end{array}$ & EC & 140 & Preterm \\
Katheria et al. (24) & EC & 20 & Term \\
Katheria et al. (47) & EC & 125 & Preterm
\end{tabular}

$\begin{array}{llll}\text { Freidl et al. (25) } & \text { EC } & 100 & \text { Term } \\ \text { McCarthy et al. (26) } & \text { BR } & 49 & \text { Term }\end{array}$

Transition

$\begin{array}{llll}\text { Cappelleri et al. (48) } & \text { BR } & 45 & \text { Preterm } \\ \text { Miletin et al. (23) } & \text { BR } & 39 & \text { Preterm }\end{array}$

Hsu et al. (49) EC $\quad 280 \quad$ Term and Preterm

Patent ductus arteriosus

Lien et al. (50)

Katheria et al. (51)

EC

EC

30

Preterm undergoing PDA ligation

Rodríguez Sánchez de

EC

Preterm 55 treated for PDA

la Blanca et al. (52)

Hsu et al. (53)

EC

18

Preterm with hsPDA

Preterm PDA, Ibuprofen non- (9) or responders (9)

\section{Effects of positioning}

Ma et al. (54)

Wu et al. (55)

Paviotti et al. (56)

EC

30

Preterm and Term

EC

34

Term

EC

Hemodynamic monitoring during transport

Boet et al. (34)

EC

30

Preterm and Term

\section{Hemodynamic effects of medication}

Katheria et al. (57)

EC

Katheria et al. (58)

Truong et al. (59)

EC

$$
21
$$

Preterm

Preterm

EC

35

NICU patients

\section{Effects of anemia/transfusion}

Weaver et al. (60)

EC

75

Preterm anemic (35) vs. no-anemic (40)

Jain et al. (61)

EC
Inter-center transfer

Primary objective

RCT comparing Delayed Cord Clamping vs. Umbilical Cord Milking

Feasibility of EC in Delivery room

RCT comparing ventilation during

Delayed Cord Clamping vs. Delayed Cord Clamping only and effects on hematocrit in the first $24 \mathrm{~h}$

Early transition within 15 min after birth

Early transition within 15 min after birth and at $2 \mathrm{~h}$ of life

Myocardial function during the first $48 \mathrm{~h}$

$\mathrm{CO}$ within the first $48 \mathrm{~h}$ in relation to adverse outcome

Normative data $>72 \mathrm{~h}$ for $\mathrm{EC}$ derived CO, SV (as well as TFC, ICON, and SVR)

Hemodynamic changes before, during, and after PDA ligation

Prediction of PDA closure with $24 \mathrm{~h}$ of age

Hemodynamic changes before, during, and after treatment

Hemodynamic effects of Ibuprofen for PDA

Cardiovascular response to Positioning

Cardiovascular response to Positioning

Cardiovascular response to Positioning

Early vs. late Caffeine

Hemodynamic effects of Sodium Bicarbonate

Hemodynamic effects of premedication for neonatal intubation

Hemodynamic effects of RBC transfusion

Hemodynamic effects of RBC transfusion
No differences in CO measured by EC between two groups

Feasible, but challenging

No differences in SV or CO measured by EC between groups

Feasible, but challenging

Feasible, but challenging

CO and SV found to increase over the first $48 \mathrm{~h}$ of life

Adverse Outcome is associated with low $\mathrm{CO}$ in the first hours followed by high $\mathrm{CO}$ in the second $24 \mathrm{~h}$

Description of EC values beyond $72 \mathrm{~h}$ in various age groups

Significant decrease in SV and CO immediately following ligation, compared to pre-surgery baseline $\mathrm{EC}$ derived $\mathrm{CO}$ in the first day is not predictive for hsPDA

Significant decrease in $\mathrm{CO} 72 \mathrm{~h}$ after treatment

Non-responders had higher CO compared to responders

Decrease SV/CO in prone position compared to supine

Decrease SV/CO in prone position compared to supine

Decrease SV/CO in supine position compared to left-lateral position

SV monitoring during transport is feasible and reliable

No differences in $\mathrm{CO}$ between groups from 2 to $24 \mathrm{~h}$ of age No differences found in CO up to $80 \mathrm{~min}$ following administration

No differences in CO before and after premedication for intubation

Increase in $\mathrm{CO}$ between 0 and 120 min post transfusion.

No difference in $\mathrm{CO}$ measurements in hour pre and post transfusion 
TABLE 2 | Continued

\begin{tabular}{|c|c|c|c|c|c|c|}
\hline Topic & Study & Technology & $N$ & Population & Primary objective & Finding \\
\hline \multicolumn{7}{|c|}{ Effects of HIE, TH, and rewarming } \\
\hline & Wu et al. (62) & EC & 20 & $\begin{array}{l}\text { Term undergoing } \mathrm{TH} \text { for } \\
\text { HIE }\end{array}$ & Hemodynamic effects of rewarming & $\begin{array}{l}\text { CO found to increase during } \\
\text { rewarming }\end{array}$ \\
\hline & Eriksen et al. (63) & EC & 25 & $\begin{array}{l}\text { Term } 15 \text { asphyxiated vs. } \\
10 \text { controls }\end{array}$ & $\begin{array}{l}\text { Hemodynamic effects of early (1st } \\
6 \mathrm{~h} \text { ) of } \mathrm{TH} \text { and to assess the effect } \\
\text { of low CO on lactate clearance }\end{array}$ & $\mathrm{CO}$ found to be reduced during $\mathrm{TH}$ \\
\hline & Forman et al. (37) & $\mathrm{BR}$ & 20 & $\begin{array}{l}\text { Term undergoing TH for } \\
\text { HIE }\end{array}$ & $\begin{array}{l}\text { Feasibility and reliability of } \\
\text { multimodal non-invasive monitoring } \\
\text { during } \mathrm{TH} \text { and rewarming for HIE }\end{array}$ & $\begin{array}{l}\text { CO found to increase during } \\
\text { rewarming }\end{array}$ \\
\hline
\end{tabular}

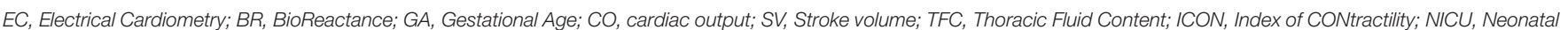

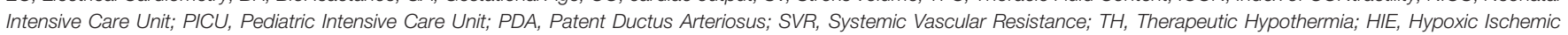
Encephalopathy; RCT, Randomized Controlled Trial; RBC, Red Blood Cell.

pre-treatment baseline CO determined by EC compared to nonPDA infants. Interestingly, non-responders to medical treatment with ibuprofen had higher CO compared to responders. EC has been utilized peri-operatively in PDA ligation and may improve management of post ligation syndrome (50).

\section{Positioning}

Three small cohort studies comparing the effect of positioning of the infant on $\mathrm{CO}$ measurements revealed differences in prone or left-lateral and supine position (54-56). Ma et al. (54) found decreased $\mathrm{SV}$ and $\mathrm{CO}$ in prone position compared to supine position using EC. This was confirmed by $\mathrm{Wu}$ et al. (55) using both EV and Echo. These results may have important implications for clinical use, particularly as many preterm infants are often nursed prone. Paviotti et al. (56) compared left lateral position to the supine position using EC technology. Both SV and $\mathrm{CO}$ were found to be decreased significantly in the supine vs. the left-lateral position.

\section{Hemodynamic Monitoring During Transport}

With ongoing centralization of neonatal care, the transportation of unstable infants born in level one or level two centers will increase. Therefore, hemodynamic monitoring during transport may facilitate more appropriate management in this specific situation. During inter-center transfer, a method of reliable monitoring of circulatory status might have an important impact on transport management decisions. SV monitoring with EC was found to be feasible in 30 infants during inter-center transfer (34). EC-derived SV was higher compared to Echo, but both methods were identified as reliable. Whether continuous NiCO results in improved post transport outcome has yet to be determined and is another area that warrants further study.

\section{Studies Evaluating Hemodynamic Effects of Medications}

Three studies have used EC for hemodynamic monitoring in neonates receiving medications including caffeine (57), sodium bicarbonate (58), and premedication for intubation (59).

In 2015, Katheria et al. used EC in a small group $(n=21)$ of non-intubated preterm infants, who were either randomized to early $(<2 \mathrm{~h})$ or late $(12 \mathrm{~h})$ administration of caffeine after birth.
Numerous indicators of systemic blood flow including SVC flow, $\mathrm{LV}$, and RV CO were estimated by Echo at a mean time of $6 \mathrm{~h}$. Serial measurements including SV, CO, mean BP, and HR were also recorded between 2 and $24 \mathrm{~h}$ of life using both EC and an umbilical artery catheter (57). No significant differences were found between the two groups in both LV CO as measured by Echo or CO, which was recorded with EC. Only a small number of studies have looked at the cardiovascular effects of caffeine in neonates. Some studies suggest an improvement in CO $(66,67)$, while others have suggested no significant change $(68,69)$. Given the timing of this study, it is possible that Echo and EC-derived $\mathrm{CO}$ measurements may have been impacted by large left to right ductal shunts, which are often a feature of the early neonatal transitional circulation.

Katheria also looked at 36 preterm infants (mean GA 26.3 weeks) who received $\mathrm{NaHO}_{3}$ in the first $24 \mathrm{~h}$ of life for metabolic acidosis. They recorded average HR, BP, CO, and cerebral oxygen tissue saturation $\left(\mathrm{CrSO}_{2}\right)$, over 10-min intervals up until $80 \mathrm{~min}$ post $\mathrm{NaHO}_{3}$ administration (58). No comparative measurements of $\mathrm{CO}$ were measured using Echo over the period of observation. One study including 16 neonates demonstrated that sodium bicarbonate induced a significant but transient rise in $\mathrm{CO}$, aortic blood flow velocity, and systolic BP (70). Other studies in adult populations have shown little cardiovascular benefits $(71,72)$.

More recently, Truong used EC to assess the hemodynamic effects of premedication in 37 infants (mean GA 31.6) requiring intubation. A combination of atropine, followed by fentanyl/morphine and finally cisatracurium was used in 36/37 infants. There was no significant difference found in CO before and after premedication. However, 17 infants did have a $\geq 20 \%$ drop in CO after intubation. Ten infants also had a $\geq 20 \%$ drop in mean BP. This decline in BP did not correlate with any fall off in CO. The use of Echo to assess cardiovascular changes during premedication and intubation is not feasible. NiCO offers an alternative non-invasive method for assessing hemodynamic changes prior to and during intubation.

\section{Hemodynamic Effects of Red Blood Cell Transfusion}

There have been two studies using EC in preterm neonates receiving red blood cell transfusions (RBC) (60, 61). Weaver et al. (60) looked at the hemodynamic characteristics of 75 
preterm infants, and compared those who had anemia requiring transfusion $(n=35)$, with a control group who were not anemic $(n=40)$. Only stable infants were included in the analysis, and any infants on mechanical ventilation, or those with suspected altered perfusion were excluded. Measurements including $\mathrm{CO}$, SV, HR variability (HRV), and complexity (HRC) were recorded using the ICON monitor and were continued for a minimum of $4 \mathrm{~h}$ in both groups of patients. The mean adjusted GA was similar in both groups, $32-33$ weeks. There was a statistically significant difference in $\mathrm{CO}$ between the non-transfused group and the transfused group prior to treatment, $0.28 \mathrm{vs} .0 .17 \mathrm{~L} / \mathrm{min}$, respectively. SV was also higher in the non-transfused group but did not reach statistical significance. For the group that was transfused, they found that CO increased over time and that this was statistically significant at all time points between 0 and $120 \mathrm{~min}$. Despite this increase, CO measurements in the transfused group still remained consistently lower than the nontransfused group.

A second study by Jain et al. (61) measured CO and nearinfrared spectroscopy (NIRS)-derived $\mathrm{CrSO}_{2}$ in 27 preterm infants in the hour prior to and the hour post transfusion. Pretransfusion oxygen delivery index (ODI) was also calculated using the formula: Hemoglobin $(\mathrm{Hb})[\mathrm{g} / \mathrm{dl}] \times \mathrm{CO}[\mathrm{L} / \mathrm{kg} / \mathrm{min}]$. There was no statistical difference identified in CO before and after transfusion. In addition, the pre-transfusion $\mathrm{CO}$ and $\mathrm{Hb}$ did not correlate with $\mathrm{CrSO}_{2}$ or in the change in $\mathrm{CrSO}_{2}$ following transfusion. It was the pre-transfusion ODI that was found to be a greater determinant of tissue perfusion. A significant correlation was found between ODI and both pre-transfusion $\mathrm{CrSO}_{2}$, and the change in $\mathrm{CrSO}_{2}$ after transfusion. This would suggest a role of $\mathrm{CO}$ monitoring to identify those preterm infants who are most likely to benefit from RBC transfusion. Numerous studies have reported a decrease in $\mathrm{CO}$ measured by echo following transfusion (73-75). Saleemi et al. (76) found no significant changes in load-dependent parameters, but instead found an improvement in myocardial contractility following transfusions. As cardiac monitoring was only continued for a short time after transfusion in the study by Weaver, the increase found in CO and $\mathrm{HRV}$ in the transfused group may not fully reflect the longerterm effects of RBC transfusions on the cardiovascular system. Further studies with $\mathrm{NiCO}$ in the post-transfusion period would be beneficial.

\section{Hypoxic Ischemic Encephalopathy, Therapeutic Hypothermia, and Rewarming}

Outcome in infants with hypoxic ischemic encephalopathy (HIE) has improved significantly since the introduction in 2008 of therapeutic hypothermia $(\mathrm{TH})$ as standard of care for infants with moderate and severe grades of encephalopathy (77). Despite this, a significant number of infants continue to have poor neurodevelopmental outcome at follow-up (77-79). Adjunct therapies are currently under investigation (80). HIE has been shown to result in myocardial ischemia and have a transient effect of myocardial function, which may further complicate cerebral perfusion (81-85). Although BP monitoring is widely available, changes in $\mathrm{CO}$ may occur independent of changes in
BP $(37,86)$. NiCO monitoring has the potential to provide a continuous, non-invasive measurement of $\mathrm{CO}$ in these infants. To date, three studies have assessed the use of NiCO in infants with HIE, specifically looking at the effect of $\mathrm{TH}$ on cardiac function $(37,62,63)$.

Eriksen et al. (63) used EC to examine CO for the first $6 \mathrm{~h}$ of life in 15 infants undergoing $\mathrm{TH}$ for moderate and severe grades of HIE compared with 10 healthy term controls. NiCO was also used to assess the effect of low $\mathrm{CO}$ on lactate clearance during the same timeframe. Five infants with HIE had NiCO measurements available prior to initiation of $\mathrm{TH}$, which showed an impairment in $\mathrm{CO}$ and $\mathrm{SV}$ when compared to healthy term controls. CO was reduced in all infants during $\mathrm{TH}$ compared with controls, but this was mainly due to a reduction in HR. In infants with HIE, rate of clearance of lactate did not correlate with CO. Of note, the rate of lactate clearance correlated with the highest Thompson score. Forman et al. (37) used BR to assess the effects of TH on $\mathrm{CO}$. They recruited 20 infants undergoing $\mathrm{TH}$ for moderate and severe grades of encephalopathy and recorded NIRS and NiCO measurements during $\mathrm{TH}$ and the rewarming period. Eight infants also had serial point of care Echos performed during the monitoring period. CO increased during the rewarming period, and this was predominantly due to an increase in heart rate. There was a strong correlation between BR and Echo-derived measurements of $\mathrm{CO}$; however, $\mathrm{NiCO}$ measurements of $\mathrm{CO}$ were consistently $27 \%$ lower than Echo measurements, similar to previous comparison studies $(21,36)$.

$\mathrm{Wu}$ et al. (62) used EC and Echo to examine changes in CO during the rewarming period in 20 infants with moderate and severe grades of HIE. Both EC and Echo derived measurements of CO increased during the rewarming period from $153 \pm 43$ $\mathrm{ml} / \mathrm{kg} / \mathrm{min}$ to $197 \pm 42 \mathrm{ml} / \mathrm{kg} / \mathrm{min}$ and $149 \pm 35 \mathrm{ml} / \mathrm{kg} / \mathrm{min}$ to $179 \pm 34 \mathrm{ml} / \mathrm{kg} / \mathrm{min}$, respectively. HR increased significantly, and SV remained unchanged. Both systemic vascular resistance and mean arterial blood pressure decreased during the rewarming period but did not meet GA thresholds for intervention.

$\mathrm{TH}$ has a significant effect on HR and thus CO. Whether this is a protective mechanism or a response to a decrease in the basal metabolic rate requires further research. NiCO monitoring during $\mathrm{TH}$ is feasible. NiCO measures correlate with previously described Echo measures of $\mathrm{CO}$ and reflect expected hemodynamic changes during TH $(86,87)$.

\section{Studies Evaluating Other Parameters Derived by NiCO Monitors}

EC devices provide a variety of other circulatory parameters, such as Cardiac contractility estimated as an Index of Contractility ("ICON"-value), its Variation of Index (VIC), LV Systolic Time Ratio (LV-STR = LVPEP/LVET), Thoracic Fluid Content (TFC), Stroke Volume Variation (SVV). The use of EC-derived TFC in respiratory distress syndrome diagnosis and management (88) requires further investigation. The same is required for the use of HRV in diagnosing sepsis or infection (89). In line with EC, BR devices display estimates of change in SV index, TFC, and LVET. Integrated in the $\mathrm{NiCO}$ devices, these parameters are available at the bedside in real-time potentially improving 
diagnosis and subsequent treatment. However, studies with larger sample sizes are needed before introduction into routine clinical care.

\section{DISCUSSION}

Neonates, and in particular preterm infants, have a very unique and complex cardiovascular system in the first days of life, which is inherently different to adult or pediatric populations. Monitoring is also very different, as the most accurate and precise methods published, such as thermodilution and cardiac MRI are just not feasible in this age group. Transthoracic Echo is the current reference for measuring cardiac performance in the neonatal population, but it has various limitations. In addition, there are conflicting reports with regard to the accuracy of Echo itself. A systematic review by Wetterslev et al. (90) comparing echocardiography to thermodilution in mainly adult studies, suggested that the two techniques are not interchangeable. Of note, many of those studies included transesophageal Echo, which is not routinely used in neonates (90). A follow-up systematic review and meta-analysis by Zhang et al. (91) concluded that there was no significant difference between the two methods. However, they also found that in certain situations, such as high $\mathrm{CO}$ or physiological structural changes, the accuracy of $\mathrm{CO}$ by echocardiography was questionable. This is obviously very relevant to the neonatal population who are subject to both these issues.

The studies to date using EC/BR in the neonatal population have been carried out only in a research setting, and many have focused on the interchangeability with Echo. However, given the limitations of Echo, comparing these two methods and calculating the bias is overly simplistic. Critchley et al. (40) eluded to this point and outlined the need to present percentage errors and limits of agreement to fully evaluate any new techniques in cardiac monitoring. They proposed that when looking at any new methods for cardiac evaluation, an acceptable limit of agreement (LOA) would be $\pm 30 \%$. However, these acceptable LOA are also reliant on the reference method having an acceptable accuracy of $\pm 10-20 \%$, which is not associated with Echo $(20,40)$.

We have outlined a range of studies including over 2,000 mostly preterm infants where EC and BR have been used. Feasibility remains a concern and many studies have reported problems with the size of the adhesive sensors particularly those using bioreactance $(20,21,36,37)$. The use of EC/BR in the delivery room has also been problematic with both time delays in recording and signal quality issues $(24,25)$. The use of these adhesives over a more extended time period has yet to be determined.

The accuracy of EC and BR is very difficult to determine without comparison to the more well-accepted methods such as thermodilution/pulmonary artery catheterization. However, this is neither safe nor ethically acceptable in this vulnerable group. Studies in neonatal animal models may allow us to better assess the precision and accuracy of these models. Other factors such as PDAs, respiratory support, and level of cardiac output have all been shown to significantly affect bias (20). The effects of other confounders on accuracy and precision would need to be explored fully in further studies. This may also provide identification of physiological vs. pathological values, rather than just a direct comparison with values obtained by other methods for cardiac output monitoring.

Non-invasive methods for cardiac evaluation in neonates are probably more important than in other population groups, given the limited tools we have in practice at present. Studies to date using EC/BR suggest that they cannot substitute Echo, but that they may offer some benefits in trend monitoring. The focus of many new cardiac monitoring techniques is comparison to the "gold standard." Feldman explained the need to move beyond this approach and instead focus on whether these new technologies can improve clinical decision making and ultimately patient outcome (92). This idea was followed by Biasis et al. (93) who pointed out that variations in cardiac output are probably more beneficial than an absolute value in most cases. They also found that positive patient outcomes using less accurate hemodynamic monitoring systems were often associated with devices that used specific therapeutic protocols. They concluded that accuracy is important and necessary, but that they also must be accompanied by outcome studies. The optimal technique-yet to be identified-should be evaluated stepwise: starting with its accuracy compared to "gold standard" and including its confounders, relation to clinically relevant outcome, estimate values for decision making (including sensitivity and specificity of cut-offs and its confounders), and last but not least inclusion in therapeutic protocols and its effects on the patient's outcomes (93).

\section{CONCLUSION}

Despite questionable interchangeability with Echo and evidence for its various confounders, both $\mathrm{EC}$ and BR are frequently used in various research settings. $\mathrm{NiCO}$ technology provides non-invasive continuous hemodynamic monitoring. As a result, this technology has the potential to positively impact on circulatory monitoring, management, and ultimately patient outcome. However, normative data or intervention thresholds from echocardiography should not be used in the interpretation of $\mathrm{NiCO}$-derived $\mathrm{SV}$ and $\mathrm{CO}$. Its implementation in treatment algorithms and its effect on clinically relevant short- and long-term outcomes need to be addressed in future research. Until this evidence is available, it should not be used in routine neonatal clinical practice.

\section{AUTHOR CONTRIBUTIONS}

CES and EMD conceived and designed the review. CES, RO'N, AAG, and EMD contributed to the drafting of the initial and the revised manuscript, critically revised the manuscript for important intellectual content, agreed on the final manuscript, and approved its submission for publication. 
All authors contributed to the article and approved the submitted version.

\section{FUNDING}

CES was supported by Deutsche Forschungsgemeinschaft (DFG, German Research Foundation) Project number 420536451 during his work on this review. AAG was supported by a Clinical

\section{REFERENCES}

1. Groves AM, Kuschel CA, Knight DB, Skinner JR. Relationship between blood pressure and blood flow in newborn preterm infants. Arch Dis Child Fetal Neonatal Edn. (2008) 93:F29-32. doi: 10.1136/adc.2006.109520

2. Kluckow M, Evans N. Relationship between blood pressure and cardiac output in preterm infants requiring mechanical ventilation. J Pediatrics. (1996) 129:506-12. doi: 10.1016/S0022-3476(96)70114-2

3. Osborn DA, Evans N, Kluckow M. Clinical detection of low upper body blood flow in very premature infants using blood pressure, capillary refill time, and central-peripheral temperature difference. Arch Dis Child Fetal Neonatal Ed. (2004) 89:F168-73. doi: 10.1136/adc.2002.023796

4. Miletin J, Pichova K, Dempsey EM. Bedside detection of low systemic flow in the very low birth weight infant on day 1 of life. Eur J Pediatr. (2009) 168:809-13. doi: 10.1007/s00431-008-0840-9

5. LeFlore JL, Engle WD. Capillary refill time is an unreliable indicator of cardiovascular status in term neonates. Adv Neonatal Care. (2005) 5:147-54. doi: 10.1016/j.adnc.2005.02.008

6. Gale C. Question 2 is capillary refill time a useful marker of haemodynamic status in neonates? Arch Dis Childh. (2010) 95:395-7. doi: $10.1136 /$ adc. 2010.186411

7. El-Khuffash A, McNamara PJ. Hemodynamic assessment and monitoring of premature infants. Clin Perinatol. (2017) 44:377-93. doi: 10.1016/j.clp.2017.02.001

8. Singh Y, Roehr CC, Tissot C, Rogerson S, Gupta S, Bohlin K, et al. Education, training, and accreditation of neonatologist performed echocardiography in Europe-framework for practice. Pediatric Res. (2018) 84(Suppl. 1):13-7. doi: 10.1038/s41390-018-0078-9

9. Finan E, Sehgal A, Khuffash AE, McNamara PJ. Targeted neonatal echocardiography services: need for standardized training and quality assurance. J Ultrasound Med. (2014) 33:1833-41. doi: $10.7863 /$ ultra.33.10.1833

10. Keren H, Burkhoff D, Squara P. Evaluation of a noninvasive continuous cardiac output monitoring system based on thoracic bioreactance. Am J Physiol Heart Circ Physiol. (2007) 293:H583-9. doi: 10.1152/ajpheart.00195.2007

11. Squara P, Denjean D, Estagnasie P, Brusset A, Dib JC, Dubois C. Noninvasive cardiac output monitoring (NICOM): a clinical validation. Intensive Care Med. (2007) 33:1191-4. doi: 10.1007/s00134-007-0640-0

12. Soleymani S, Borzage M, Seri I. Hemodynamic monitoring in neonates: advances and challenges. J Perinatol. (2010) 30:S38-45. doi: $10.1038 /$ jp. 2010.101

13. Vrancken SL, van Heijst AF, de Boode WP. Neonatal hemodynamics: from developmental physiology to comprehensive monitoring. Front Pediatr. (2018) 6:87. doi: 10.3389/fped.2018.00087

14. Patterson RP. Fundamentals of impedance cardiography. IEEE Eng Med Biol Mag. (1989) 8:35-8. doi: 10.1109/51.32403

15. Kubicek WG, Karnegis JN, Patterson RP, Witsoe DA, Mattson RH. Development and evaluation of an impedance cardiac output system. Aerosp Med. (1966) 37:1208-12.

16. Osypka MJ, Bernstein DP. Electrophysiologic principles and theory of stroke volume determination by thoracic electrical bioimpedance. AACN Clin Issues. (1999) 10:385-99. doi: 10.1097/00044067-199908000-00008

17. Noori S, Drabu B, Soleymani S, Seri I. Continuous non-invasive cardiac output measurements in the neonate by electrical velocimetry: a comparison
Research Fellowship grant from the National Children's Research Centre, Ireland (D/18/6).

\section{ACKNOWLEDGMENTS}

We would like to acknowledge the support of Deutsche Forschungsgemeinschaft (DFG, German Research Foundation) and the National Children's Research Centre, Ireland (D/18/6). with echocardiography. Arch Dis Child Fetal Neonatal Ed. (2012) 97:F340-3. doi: 10.1136/fetalneonatal-2011-301090

18. Squara P, (eds). Bioreactance: A New Method for Non-invasive Cardiac Output Monitoring. Berlin; Heidelberg: Springer Berlin Heidelberg (2008).

19. Squara P, Burkhoff D. Bioreactance $\AA$. In: Vincent JL, Hall JB, editors. Encyclopedia of Intensive Care Medicine. Berlin; Heidelberg: Springer Berlin Heidelberg (2012). p. 317-21.

20. Van Wyk L, Smith J, Lawrenson J, de Boode WP. Agreement of cardiac output measurements between bioreactance and transthoracic echocardiography in preterm infants during the transitional phase: a single-centre, prospective study. Neonatology. (2020) 117:271-8. doi: 10.1159/000506203

21. Weisz DE, Jain A, McNamara PJ, EL-Khuffash A. Non-invasive cardiac output monitoring in neonates using bioreactance: a comparison with echocardiography. Neonatology. (2012) 102:61-7. doi: 10.1159/000337295

22. Van Laere D, Voeten M, O' Toole JM, Dempsey E. Monitoring circulation during transition in extreme low gestational age newborns: what's on the horizon? Front Pediatr. (2018) 6:74. doi: 10.3389/fped.2018.00074

23. Miletin J, Semberova J, Martin AM, Janota J, Stranak Z. Low cardiac output measured by bioreactance and adverse outcome in preterm infants with birth weight less than 1250 g. Early Hum Dev. (2020) 149:105153. doi: 10.1016/j.earlhumdev.2020.105153

24. Katheria AC, Wozniak M, Harari D, Arnell K, Petruzzelli D, Finer NN. Measuring cardiac changes using electrical impedance during delayed cord clamping: a feasibility trial. Matern Health Neonatol Perinatol. (2015) 1:15. doi: 10.1186/s40748-015-0016-3

25. Freidl T, Baik N, Pichler G, Schwaberger B, Zingerle B, Avian A, et al. Haemodynamic transition after birth: a new tool for non-invasive cardiac output monitoring. Neonatology. (2017) 111:55-60. doi: 10.1159/000446468

26. McCarthy KN, Pavel A, Garvey AA, Hawke A-L, Levins C, Livingstone V, et al. Feasibility of non-invasive cardiac output monitoring at birth using electrical bio reactance in term infants. Arch Dis Child Fetal Neonatal Ed. (2020). doi: 10.1136/archdischild-2019-318244. [Epub ahead of print].

27. Grollmuss O, Demontoux S, Capderou A, Serraf A, Belli E. Electrical velocimetry as a tool for measuring cardiac output in small infants after heart surgery. Intensive Care Med. (2012) 38:1032-9. doi: 10.1007/s00134-012-2530-3

28. Grollmuss O, Gonzalez P. Non-invasive cardiac output measurement in low and very low birth weight infants: a method comparison. Front Pediatr. (2014) 2:16. doi: 10.3389/fped.2014.00016

29. Song R, Rich W, Kim JH, Finer NN, Katheria AC. The use of electrical cardiometry for continuous cardiac output monitoring in preterm neonates: a validation study. Am J Perinatol. (2014) 31:1105-10. doi: 10.1055/s-0034-1371707

30. Blohm ME, Obrecht D, Hartwich J, Mueller GC, Kersten JF, Weil J, et al. Impedance cardiography (electrical velocimetry) and transthoracic echocardiography for non-invasive cardiac output monitoring in pediatric intensive care patients: a prospective single-center observational study. Crit Care. (2014) 18:603. doi: 10.1186/s13054-0140603-0

31. Boet A, Jourdain G, Capderou A, Grollmuss O, Labrune P, De Luca D, et al. PS-021 electrical cardiometry stroke volume evaluation in nicu: comparison with functional echocardiography. Arch Dis Childh. (2014) 99(Suppl. 2):A119. doi: 10.1136/archdischild-2014-307384.317

32. Torigoe T, Sato S, Nagayama Y, Sato T, Yamazaki H. Influence of patent ductus arteriosus and ventilators on electrical velocimetry for measuring cardiac 
output in very-low/low birth weight infants. J Perinatol. (2015) 35:485-9. doi: $10.1038 /$ jp.2014.245

33. Boet A, Jourdain G, Demontoux S, De Luca D. Stroke volume and cardiac output evaluation by electrical cardiometry: accuracy and reference nomograms in hemodynamically stable preterm neonates. J Perinatol. (2016) 36:748-52. doi: 10.1038/jp.2016.65

34. Boet A, Jourdain G, Demontoux S, Hascoet S, Tissieres P, Rucker-Martin $\mathrm{C}$, et al. Basic hemodynamic monitoring using ultrasound or electrical cardiometry during transportation of neonates and infants. Pediatr Crit Care Me. (2017) 18:E488-93. doi: 10.1097/PCC.0000000000001298

35. Hsu KH, Wu TW, Wu IH, Lai MY, Hsu SY, Huang HW, et al. Electrical cardiometry to monitor cardiac output in preterm infants with patent ductus arteriosus: a comparison with echocardiography. Neonatology. (2017) 112:231-7. doi: 10.1159/000475774

36. Weisz DE, Jain A, Ting J, McNamara PJ, El-Khuffash A. Non-invasive cardiac output monitoring in preterm infants undergoing patent ductus arteriosus ligation: a comparison with echocardiography. Neonatology. (2014) 106:3306. doi: $10.1159 / 000365278$

37. Forman E, Breatnach CR, Ryan S, Semberova J, Miletin J, Foran A, et al. Noninvasive continuous cardiac output and cerebral perfusion monitoring in term infants with neonatal encephalopathy: assessment of feasibility and reliability. Pediatr Res. (2017) 82:789-95. doi: 10.1038/pr.2017.154

38. Cecconi M, Rhodes A, Poloniecki J, Della Rocca G, Grounds RM. Bench-tobedside review: the importance of the precision of the reference technique in method comparison studies-with specific reference to the measurement of cardiac output. Crit Care. (2009) 13:201. doi: 10.1186/cc7129

39. Ficial B, Finnemore AE, Cox DJ, Broadhouse KM, Price AN, Durighel G, et al. Validation study of the accuracy of echocardiographic measurements of systemic blood flow volume in newborn infants. J Am Soc Echocardiogr. (2013) 26:1365-71. doi: 10.1016/j.echo.2013.08.019

40. Critchley LA, Critchley JA. A meta-analysis of studies using bias and precision statistics to compare cardiac output measurement techniques. J Clin Monit Comput. (1999) 15:85-91.

41. Suehiro K, Joosten A, Murphy LS, Desebbe O, Alexander B, Kim SH, et al. Accuracy and precision of minimally-invasive cardiac output monitoring in children: a systematic review and meta-analysis. J Clin Monit Comput. (2016) 30:603-20. doi: 10.1007/s10877-015-9757-9

42. Sanders M, Servaas S, Slagt C. Accuracy and precision of non-invasive cardiac output monitoring by electrical cardiometry: a systematic review and meta-analysis. J Clin Monit Comput. (2019) 34:433-60. doi: 10.1007/s10877-019-00330-y

43. Evans N, Kluckow M. Early determinants of right and left ventricular output in ventilated preterm infants. Arch Dis Child Fetal Neonatal Ed. (1996) 74:F88-94. doi: 10.1136/fn.74.2.F88

44. Evans N, Iyer P. Incompetence of the foramen ovale in preterm infants supported by mechanical ventilation. J Pediatr. (1994) 125(5 Pt 1):786-92. doi: 10.1016/S0022-3476(06)80184-8

45. Evans N. Current controversies in the diagnosis and treatment of patent ductus arteriosus in preterm infants. Adv Neonatal Care. (2003) 3:168-77. doi: 10.1016/S1536-0903(03)00143-7

46. Katheria AC, Truong G, Cousins L, Oshiro B, Finer NN. Umbilical cord milking versus delayed cord clamping in preterm infants. Pediatrics. (2015) 136:61-9. doi: 10.1542/peds.2015-0368

47. Katheria A, Poeltler D, Durham J, Steen J, Rich W, Arnell K, et al. Neonatal resuscitation with an intact cord: a randomized clinical trial. J Pediatr. (2016) 178:75-80.e3. doi: 10.1016/j.jpeds.2016.07.053

48. Cappelleri A, Bussmann N, Harvey S, Levy PT, Franklin O, El-Khuffash A. Myocardial function in late preterm infants during the transitional period: comprehensive appraisal with deformation mechanics and noninvasive cardiac output monitoring. Cardiol Young. (2020) 30:249-55. doi: 10.1017/S1047951119003020

49. Hsu KH, Wu TW, Wang YC, Lim WH, Lee CC, Lien R. Hemodynamic reference for neonates of different age and weight: a pilot study with electrical cardiometry. J Perinatol. (2016) 36:481-5. doi: 10.1038/jp.2016.2

50. Lien R, Hsu KH, Chu JJ, Chang YS. Hemodynamic alterations recorded by electrical cardiometry during ligation of ductus arteriosus in preterm infants. Eur J Pediatr. (2015) 174:543-50. doi: 10.1007/s00431-014-2437-9
51. Katheria V, Poeltler DM, Brown MK, Hassen KO, Patel D, Rich W, et al. Early prediction of a significant patent ductus arteriosus in infants $<32$ weeks gestational age. J Neonatal Perinatal Med. (2018) 11:265-71. doi: 10.3233/NPM-1771

52. Rodriguez Sanchez de la Blanca A, Sanchez Luna M, Gonzalez Pacheco N, Arriaga Redondo M, Navarro Patino N. Electrical velocimetry for noninvasive monitoring of the closure of the ductus arteriosus in preterm infants. Eur J Pediatr. (2018) 177:229-35. doi: 10.1007/s00431-017-3063-0

53. Hsu KH, Wu TW, Wu IH, Lai MY, Hsu SY, Huang HW, et al. Baseline cardiac output and its alterations during ibuprofen treatment for patent ductus arteriosus in preterm infants. BMC Pediatr. (2019) 19:179. doi: $10.1186 / \mathrm{s} 12887-019-1560-1$

54. Ma M, Noori S, Maarek JM, Holschneider DP, Rubinstein EH, Seri I. Prone positioning decreases cardiac output and increases systemic vascular resistance in neonates. J Perinatol. (2015) 35:424-7. doi: 10.1038/jp.20 14.230

55. Wu TW, Lien RI, Seri I, Noori S. Changes in cardiac output and cerebral oxygenation during prone and supine sleep positioning in healthy term infants. Arch Dis Child Fetal Neonatal Ed. (2017) 102:F483-F9. doi: 10.1136/archdischild-2016-311769

56. Paviotti G, Todero S, Demarini S. Cardiac output decreases and systemic vascular resistance increases in newborns placed in the left-lateral position. J Perinatol. (2017) 37:563-5. doi: 10.1038/jp.2016.251

57. Katheria AC, Sauberan JB, Akotia D, Rich W, Durham J, Finer NN. A pilot randomized controlled trial of early versus routine caffeine in extremely premature infants. Am J Perinatol. (2015) 32:879-86. doi: $10.1055 / \mathrm{s}-0034-1543981$

58. Katheria AC, Brown MK, Hassan K, Poeltler DM, Patel DA, Brown VK, et al. Hemodynamic effects of sodium bicarbonate administration. J Perinatol. (2017) 37:518-20. doi: 10.1038/jp.2016.258

59. Truong L, Kim JH, Katheria AC, Finer NN, Marc-Aurele K. Haemodynamic effects of premedication for neonatal intubation: an observational study. Arch Dis Child Fetal Neonatal Ed. (2020) 105:123-7. doi: 10.1136/archdischild-2018-316235

60. Weaver B, Guerreso K, Conner EA, Russell K, Vogel R, Rodriguez M. Hemodynamics and perfusion in premature infants during transfusion. AACN Adv Crit Care. (2018) 29:126-37. doi: 10.4037/aacnacc2018402

61. Jain D, D'Ugard C, Bancalari E, Claure N. Cerebral oxygenation in preterm infants receiving transfusion. Pediatr Res. (2019) 85:786-9. doi: 10.1038/s41390-018-0266-7

62. Wu TW, Tamrazi B, Soleymani S, Seri I, Noori S. Hemodynamic changes during rewarming phase of whole-body hypothermia therapy in neonates with hypoxic-ischemic encephalopathy. J Pediatr. (2018) 197:68-74 e2. doi: 10.1016/j.jpeds.2018.01.067

63. Eriksen VR, Trautner S, Hahn GH, Greisen G. Lactate acidosis and cardiac output during initial therapeutic cooling in asphyxiated newborn infants. PLoS ONE. (2019) 14:e0213537. doi: 10.1371/journal.pone.0213537

64. van Vonderen JJ, Roest AA, Siew ML, Blom NA, van Lith JM, Walther FJ, et al. Noninvasive measurements of hemodynamic transition directly after birth. Pediatr Res. (2014) 75:448-52. doi: 10.1038/pr.2013.241

65. Katheria AC, Leone TA, Woelkers D, Garey DM, Rich W, Finer NN. The effects of umbilical cord milking on hemodynamics and neonatal outcomes in premature neonates. J Pediatr. (2014) 164:1045-50.e1. doi: $10.1016 /$ j.jpeds.2014.01.024

66. Walther FJ, Erickson R, Sims ME. Cardiovascular effects of caffeine therapy in preterm infants. Am J Dis Child. (1990) 144:1164-6. doi: 10.1001/archpedi.1990.02150340110035

67. Soloveychik V, Bin-Nun A, Ionchev A, Sriram S, Meadow W. Acute hemodynamic effects of caffeine administration in premature infants. $J$ Perinatol. (2009) 29:205-8. doi: 10.1038/jp.2008.193

68. Tracy MB, Klimek J, Hinder M, Ponnampalam G, Tracy SK. Does caffeine impair cerebral oxygenation and blood flow velocity in preterm infants? Acta Paediatr. (2010) 99:1319-23. doi: 10.1111/j.1651-2227.2010. 01828.x

69. Hoecker C, Nelle M, Poeschl J, Beedgen B, Linderkamp O. Caffeine impairs cerebral and intestinal blood flow velocity in preterm infants. Pediatrics. (2002) 109:784-7. doi: 10.1542/peds.109.5.784 
70. Fanconi S, Burger R, Ghelfi D, Uehlinger J, Arbenz U. Hemodynamic effects of sodium bicarbonate in critically ill neonates. Intensive Care Med. (1993) 19:65-9. doi: 10.1007/BF01708362

71. Mathieu D, Neviere R, Billard V, Fleyfel M, Wattel F. Effects of bicarbonate therapy on hemodynamics and tissue oxygenation in patients with lactic acidosis: a prospective, controlled clinical study. Crit Care Med. (1991) 19:1352-6. doi: 10.1097/00003246-199111000-00008

72. Cooper DJ, Walley KR, Wiggs BR, Russell JA. Bicarbonate does not improve hemodynamics in critically ill patients who have lactic acidosis a prospective, controlled clinical study. Ann Intern Med. (1990) 112:492-8. doi: 10.7326/0003-4819-112-7-492

73. Fredrickson LK, Bell EF, Cress GA, Johnson KJ, Zimmerman MB, Mahoney LT, et al. Acute physiological effects of packed red blood cell transfusion in preterm infants with different degrees of anaemia. Arch Dis Child Fetal Neonatal Ed. (2011) 96:F249-53. doi: 10.1136/adc.2010.191023

74. Kanmaz HG, Sarikabadayi YU, Canpolat E, Altug N, Oguz SS, Dilmen U. Effects of red cell transfusion on cardiac output and perfusion index in preterm infants. Early Hum Dev. (2013) 89:683-6. doi: 10.1016/j.earlhumdev.2013.04.018

75. Quante M, Pulzer F, Blaser A, Gebauer C, Kluge J, Robel-Tillig E. Effects of anaemia on haemodynamic and clinical parameters in apparently stable preterm infants. Blood Transfus. (2013) 11:227-32. doi: 10.2450/2012.0171-11

76. Saleemi MS, Bruton K, El-Khuffash A, Kirkham C, Franklin O, Corcoran JD. Myocardial assessment using tissue doppler imaging in preterm very low-birth weight infants before and after red blood cell transfusion. J Perinatol. (2013) 33:681-6. doi: 10.1038/jp.2013.39

77. Jacobs SE, Berg M, Hunt R, Tarnow-Mordi WO, Inder TE, Davis PG. Cooling for newborns with hypoxic ischaemic encephalopathy. Cochrane Database Syst Rev. (2013) 2013:CD003311. doi: 10.1002/14651858.CD003311.pub3

78. Shankaran S, Laptook AR, Ehrenkranz RA, Tyson JE, McDonald SA, Donovan EF, et al. Whole-body hypothermia for neonates with hypoxic-ischemic encephalopathy. N Engl J Med. (2005) 353:1574-84. doi: 10.1056/NEJMcps050929

79. Higgins RD, Raju TN, Perlman J, Azzopardi DV, Blackmon LR, Clark RH, et al. Hypothermia and perinatal asphyxia: executive summary of the National Institute of child health and human development workshop. J Pediatrics. (2006) 148:170-5. doi: 10.1016/j.jpeds.2005.12.009

80. van Bel F, Groenendaal F. Birth asphyxia-induced brain damage: the long road to optimal reduction and prevention! Pediatr Med. (2020) 3:3. doi: $10.21037 / \mathrm{pm} .2019 .11 .02$

81. Rowe RD, Hoffman T. Transient myocardial ischemia of the newborn infant: a form of severe cardiorespiratory distress in full-term infants. $J$ Pediatrics. (1972) 81:243-50. doi: 10.1016/S0022-3476(72)80290-7

82. Barberi I, Calabro MP, Cordaro S, Gitto E, Sottile A, Prudente D, et al. Myocardial ischaemia in neonates with perinatal asphyxia electrocardiographic, echocardiographic and enzymatic correlations. Eur J Pediatrics. (1999) 158:742-7. doi: 10.1007/s004310051192

83. Wei Y, Xu J, Xu T, Fan J, Tao S. Left ventricular systolic function of newborns with asphyxia evaluated by tissue doppler imaging. Pediatr Cardiol. (2009) 30:741-6. doi: 10.1007/s00246-009-9421-6
84. Giesinger RE, El Shahed AI, Castaldo MP, Breatnach CR, Chau V, Whyte $\mathrm{HE}$, et al. Impaired right ventricular performance is associated with adverse outcome after hypoxic ischemic encephalopathy. Am J Respir Crit Care Med. (2019) 200:1294-305. doi: 10.1164/rccm.201903-0583OC

85. Van Bel F, Walther FJ. Myocardial dysfunction and cerebral blood flow velocity following birth asphyxia. Acta Paediatr Scand. (1990) 79:756-62. doi: 10.1111/j.1651-2227.1990.tb11551.x

86. Gebauer CM, Knuepfer M, Robel-Tillig E, Pulzer F, Vogtmann C. Hemodynamics among neonates with hypoxic-ischemic encephalopathy during whole-body hypothermia and passive rewarming. Pediatrics. (2006) 117:843-50. doi: 10.1542/peds.2004-1587

87. Wood T, Thoresen M. Physiological responses to hypothermia Semin Fetal Neonatal Med. (2015) 20:87-96. doi: 10.1016/j.siny.2014 10.005

88. Paviotti G, De Cunto A, Moressa V, Bettiol C, Demarini S. Thoracic fluid content by electric bioimpedance correlates with respiratory distress in newborns. J Perinatol. (2017) 37:1024-7. doi: 10.1038/jp.2017.100

89. Bohanon FJ, Mrazek AA, Shabana MT, Mims S, Radhakrishnan GL, Kramer GC, et al. Heart rate variability analysis is more sensitive at identifying neonatal sepsis than conventional vital signs. Am J Surg. (2015) 210:661-7. doi: 10.1016/j.amjsurg.2015.06.002

90. Wetterslev M, Møller-Sørensen H, Johansen RR, Perner A. Systematic review of cardiac output measurements by echocardiography vs. thermodilution: the techniques are not interchangeable. Intensive Care Medicine. (2016) 42:122333. doi: 10.1007/s00134-016-4258-y

91. Zhang Y, Wang Y, Shi J, Hua Z, Xu J. Cardiac output measurements via echocardiography versus thermodilution: a systematic review and meta-analysis. PLoS ONE. (2019) 14:e0222105. doi: 10.1371/journal.pone. 0222105

92. Feldman JM. Is it a bird? Is it a plane? The role of patient monitors in medical decision making. Anesth Analg. (2009) 108:707-10. doi: 10.1213/ane.0b013e318196c7b6

93. Biais M, Lanchon R, Lefrant JY. Accuracy of a cardiac output monitor: is it a relevant issue without an adequate therapeutic algorithm? Anaesth Crit Care Pain Med. (2016) 35:243-4. doi: 10.1016/j.accpm.2016.06.003

Conflict of Interest: CES and EMD received an ICON device (Osypka Medical, Berlin, Germany) free of charge for 2 years.

The remaining authors declare that the research was conducted in the absence of any commercial or financial relationships that could be construed as a potential conflict of interest.

Copyright (C) 2021 O'Neill, Dempsey, Garvey and Schwarz. This is an open-access article distributed under the terms of the Creative Commons Attribution License (CC $B Y)$. The use, distribution or reproduction in other forums is permitted, provided the original author(s) and the copyright owner(s) are credited and that the original publication in this journal is cited, in accordance with accepted academic practice. No use, distribution or reproduction is permitted which does not comply with these terms. 